\title{
Solvent extraction of scandium from lateritic nickel- cobalt ores using different organic reagents
}

\author{
Ece Ferizoğlu1,2,a, Şerif Kaya ${ }^{1}$, Yavuz A. Topkaya ${ }^{2}$ \\ ${ }^{1}$ Metallurgical and Materials Engineering, METU,06800 Çankaya Ankara, Turkey \\ ${ }^{2}$ Meta Nikel Kobalt A.Ş. (Zorlu Group), 06520 Balgat Ankara, Turkey
}

\begin{abstract}
Scandium is the most important and strategic metal that can be recovered as a byproduct from lateritic nickel-cobalt ores. In this research, different extractants were investigated in order to extract scandium from a sulfate medium by a using a solvent extraction method. Generally, the organic extractants are classified as acidic, neutral and basic organophosphorus compounds. However, in solvent extraction of scandium, the acidic and neutral organophosphorus compounds are preferred due to their higher extraction efficiencies. Thus, the aim of the present study was to compare the scandium extraction efficiencies of some acidic and neutral organic reagents. For this reason, Ionquest 290 (Bis(2,4,4-trimethylpenthyl) phosphonic acid), DEHPA (Di(2-ethylhexyl) phosphoric acid), Cyanex 272 ((Bis(2,4,4trimethylpentyl) phosphinic acid) which are acidic organophosphorus compounds, and Cyanex 923 (Trialkylphosphine oxide), which is a neutral organophosphorus compound, were used. The extraction capacities of these organics were studied with respect to the extractant concentration at same $\mathrm{pH}$ and phase ratio. As a result of the study, DEHPA was found to have higher scandium extraction efficiency with lower iron extraction at $\mathrm{pH}=0.55$ at a phase ratio of 10:1=A:O.
\end{abstract}

\footnotetext{
${ }^{a}$ Corresponding author: eceferi@gmail.com
} 